\title{
Ações para conscientização e prática da educação ambiental na cidade de Patos / PB/ Brasil
}

\author{
Actions for awareness and practice of environmental education in the city \\ of Patos / PB/Brazil
}

\section{Carina Cristina Agnes Calegari}

Centro Universitário de Patos- UNIFIP- Belo Horizonte- Paraíba - Brasil ORCID https://orcid.org/0000-0002-1399-5428

\section{Leandro Calegari}

Universidade Federal de Campina Grande, campus Patos-Santa Cicilia, PatosParaíba - Brasil ORCID https://orcid.org/0000-0003-2967-2671

\section{Alana Candeia de Melo}

Centro Universitário de Patos- UNIFIP- Belo Horizonte- Paraíba - Brasil ORCID https://orcid.org/0000-0001-5849-9850

\section{Edevaldo da Silva}

Universidade Federal de Campina Grande, campus Patos - Santa Cicilia, PatosParaíba - Brasil ORCID https://orcid.org/0000-0002-8245-3438

\section{Joedla Rodrigues de Lima}

Universidade Federal de Campina Grande, campus Patos - Santa Cicilia, PatosParaíba - Brasil ORCID https://orcid.org/0000-0001-6617-2858

Resumo: A pesquisa resgata atividades desenvolvidas junto ao projeto de extensão Florestal Recicla que compõe o Programa de Ações para a Sustentabilidade Socioambiental (PASS), da Universidade Federal de Campina Grande, Campus de Patos (CSTR/UFCG). Este trabalho teve como motivação inicial a experiência profissional da autora, sob orientação dos coautores, atuando como educadora e geógrafa na iniciativa de oferecer contribuições relevantes às questões socioambientais, pela busca do consumo consciente e sustentável através da educação formal e não formal junto às comunidades, escolas e aos alunos graduandos que fazem parte do Programa. $O$ estudo teve como objetivos capacitar alunos da equipe do PASS descrevendo as noções básicas sobre Educação Ambiental, colaborar com o blog Educador Ambiental-Patos no envio de textos, desenvolver palestras e oficinas aos alunos da Escola Pública, inteirando-os sobre o Meio Ambiente, o consumo consciente e os benefícios advindos da reciclagem, pesquisar textos e imagens afins ao Programa, para incluí-los no Boletim Florestal Recicla e criar objetos reutilizando os materiais reciclados. Através deste artigo procurou-se demonstrar que o papel do educador é trabalhar pequenas mudanças diárias que podem fazer a diferença na sociedade capitalista atual. Este é o novo desafio 
da educação e que não há como pensar Educação Ambiental desvinculada de valores tais como: solidariedade, respeito mútuo, responsabilidade individual e comprometimento. Embora não se possam resolver todos os problemas ambientais, 0 PASS procura desenvolver sua ênfase na educação, replicando experiências e sensibilizando quanto à necessidade de uma postura ambientalmente ativa destinada a busca da sustentabilidade.

Palavras-chave: Educação Ambiental. Experiência. Re-educação. Valores socioambientais

Abstract: This research presents activities developed alongside the extension project Florestal Recicla that constitutes the Action Program for Socio-environmental Sustainability (Programa de Ações para a Sustentabilidade Socioambiental - PASS), at Universidade Federal de Campina Grande (Federal University of Campina Grande), Patos Campus (CSTR / UFCG). This work was initially motivated by the author's professional experience, under the guidance of co-authors, acting as an educator and a geographer with an initiative to make relevant contributions to environmental issues, in the pursuit of sustainable and responsible consumption through formal and non-formal education with communities, schools and undergraduate students being part of the program. The study aimed to empower students in the PASS team describing the basics of Environmental Education, collaborate with the blog Educador Ambiental-Patos (Environmental Educator blog) by sending texts, giving lectures and workshops to students from public school, informing them of environment, conscientious consumption and the benefits of recycling, researching texts and images related to the Program in order to include them in the Florestal Recicla Bulletin and creating objects and reusing reusable materials. The analysis of the article addresses that the role of the educator is to work on small and daily changes that can make a difference in this current capitalist society. This is the new challenge of education and there is no other way of thinking of Environmental Education disengaged from values such as solidarity, mutual respect, individual responsibility and commitment. Although it will not solve all environmental problems, PASS seeks to develop its emphasis on education, replicating experiences and sensitizing about the need for an environmentally active position in pursuit of sustainability.

Keywords: Environmental Education. Experience. Re-education. Socio-environmental values.

\section{Introdução}

A construção do conhecimento sobre uma sociedade requer a compreensão de quem são as pessoas que a compõe, quais são suas necessidades, aspirações e, sobretudo, como elas desejam compartilhar seus valores para a construção de um futuro cujas premissas possam ser orientadas pelos princípios da sustentabilidade e do respeito à individualidade e direitos de escolha. 
Embora seja comum dizer que a abordagem ambiental deva ser de abrangência geral e que devemos pensar globalmente e agir localmente, o que percebemos muitas vezes é uma práxis que reforça a forma incorreta de lidar com o meio ambiente, não levando em consideração aspectos importantes relacionados à cultura popular local. Existe todo um conhecimento cultural que precisa ser estimulado para construir-se uma nova concepção da relação do homem com o meio ambiente, haja vista que não há muito incentivo para que as pessoas reflitam sobre o seu comportamento no que se refere ao consumo e ao uso insustentável dos recursos naturais.

Unir Educação Ambiental com as vivências escolares e a construção do conhecimento é parte fundamental da educação. A Educação Ambiental nas escolas é um processo que deve durar para toda a vida e pode ajudar a tornar relevante a educação geral, começando pela educação infantil. Falar em Educação Ambiental é quase uma redundância porque como bem afirma Grünn (1996), toda educação é ambiental, já que nascemos em um ambiente e nele vivemos durante toda nossa vida. Comprometendo e colocando a Educação Ambiental como prática dos princípios básicos de sustentabilidade, a oportunidade de avaliar questões voltadas ao meio ambiente, fica a critério do homem que a executa de acordo com sua ética/moral sobre o meio que vive. No entanto, pode acontecer que alguém queira saber o que é meio ambiente e, neste caso, incorremos no velho modus operandi de controle ambiental no final da linha, quando na verdade deveríamos estar atuando na causa e, não somente, na consequência.

Por ser parte integrante da sociedade e saber que as questões socioambientais são uma pauta urgente, é imprescindível atuar co-responsavelmente na sua transformação buscando construir uma sociedade mais justa, feliz e sustentável. Diante do exposto, este trabalho tem como objetivo geral contribuir com o Programa Ações para a Sustentabilidade Socioambiental (PASS) por meio de atividades socioeducativas e ambientais que promovam a sustentabilidade, transformando-se em importante contribuição no sentido de responder às demandas da sociedade local que trabalha na construção de novos hábitos em consonância com a responsabilidade socioambiental.

Como hipótese de trabalho, queríamos comprovar se o PASS estava promovendo mudança de atitudes e hábitos com o desenvolvimento de suas atividades relacionadas com o meio ambiente e a sustentabilidade, e se estava contribuindo de forma concreta para a formação de uma equipe que de forma continuada atuasse em diversos segmentos da sociedade local.

\section{Materiais e métodos}

O referido estudo caracterizou-se como uma pesquisa de natureza exploratória, realizada durante o período de maio a dezembro de 2012, cuja metodologia incluiu a avaliação de resultados parciais da experiência, promovendo uma compreensão holística da realidade socioambiental. 
Metodologicamente trabalhou-se com a pesquisa ação participativa, com técnicas de sensibilização para o reconhecimento dos problemas ambientais e para a mudança de atitudes em relação a valores éticos e de consumo, adaptando o modo de viabilização do reaproveitamento dos materiais recicláveis.

Durante o desenvolvimento do trabalho buscou-se explicitar os diferentes pressupostos que sustentam cada uma das ações de Educação Ambiental, para ao acionarmos uma delas, sabermos os

motivos pelos quais o estamos fazendo e que resultados podemos esperar, sem esquecer que nunca controlamos completamente o processo de aprendizagem, pelo fato de este envolver uma relação aberta com o outro (CARVALHO, 2008).

Como local de trabalho contamos com a colaboração do PASS da Universidade Federal de Campina Grande, Campus de Patos (CSTR/UFCG), localizada na Rodovia Patos-Teixeira km 01, Av. Universitária, Santa Cecília - Patos/PB/Brasil (Figura 1).

Figura 1- Vista aérea do CSTR, local de trabalho

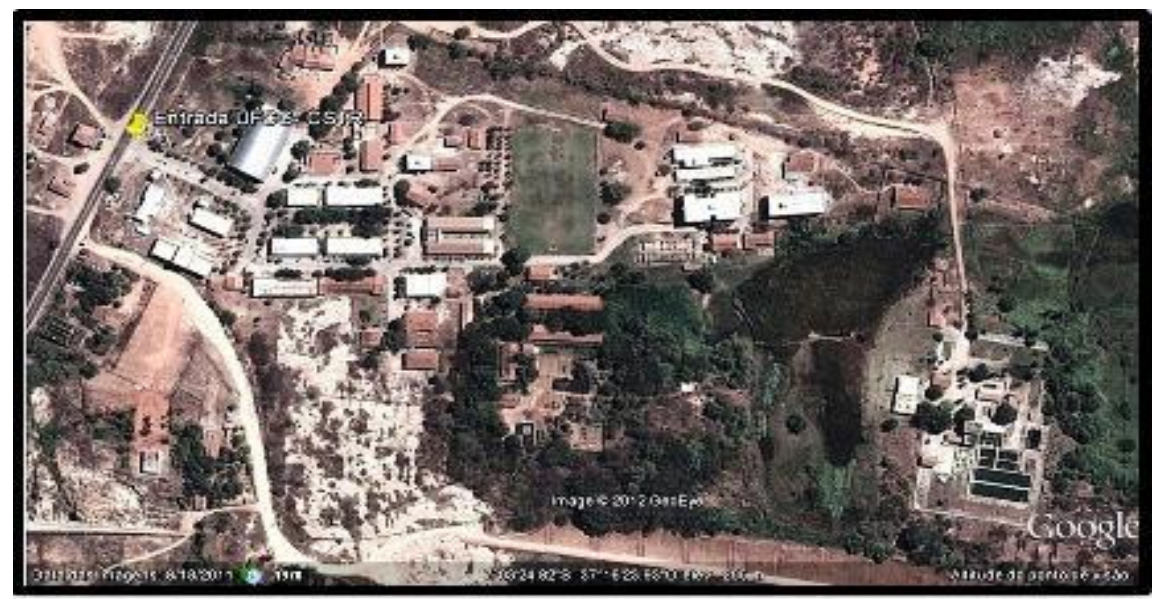

Fonte: Google Earth (agosto de 2011)

Para facilitar a compreensão do leitor, foram selecionadas experiências e atividades que possibilitassem um melhor acompanhamento da proposta e sua posterior análise. Num primeiro momento a pesquisa foi desenvolvida mediante a realização de levantamento bibliográfico sobre as noções básicas de Educação Ambiental (EA). Material selecionado e apresentado para a equipe de alunos universitários que compõem o PASS.

O segundo momento do trabalho foi à elaboração de material didático digital com o tema "Especial de Festas Juninas" sendo que os participantes, deveriam coletar artigos, notícias, documentários e imagens que tivessem afinidade com o projeto tendo em vista a colaboração com o blog Educador Ambiental Patos. Outra ação prevista foi à realização de palestras, com apresentações de vídeos ecológicos, desenvolvidos na escola e posterior realização de oficinas enfocando o conceito de sustentabilidade ambiental, econômica e social e a reutilização de materiais reciclados. 
A avaliação foi contínua em todos os procedimentos durante a execução das atividades através da observação, reação-ação, tanto dos alunos da equipe do PASS, como alunos e professores das Escolas e dos próprios autores envolvidos no projeto.

\section{Resultados e discussão}

Diálogo aberto com os alunos da equipe PASS: noções básicas sobre educação ambiental

A Educação Ambiental, como qualquer outra área de conhecimento, possui especificidades conceituais que devem ser entendidas com clareza se nosso objetivo é desenvolver atividades, que respeitem os diferentes ecossistemas (físico, biológico e social) e as culturas humanas.

Para este diálogo aberto, realizado em maio de 2012, com alunos universitários da equipe do PASS, graduandos do Curso de Engenharia Florestal (4) e graduandos do Curso de Ciências Biológicas (3), foi utilizado o Laboratório de Tecnologia da Madeira da Universidade Federal de Campina Grande, Campus de Patos (CSTR/UFCG).

Figura 2 - Diálogo aberto com alunos da equipe PASS

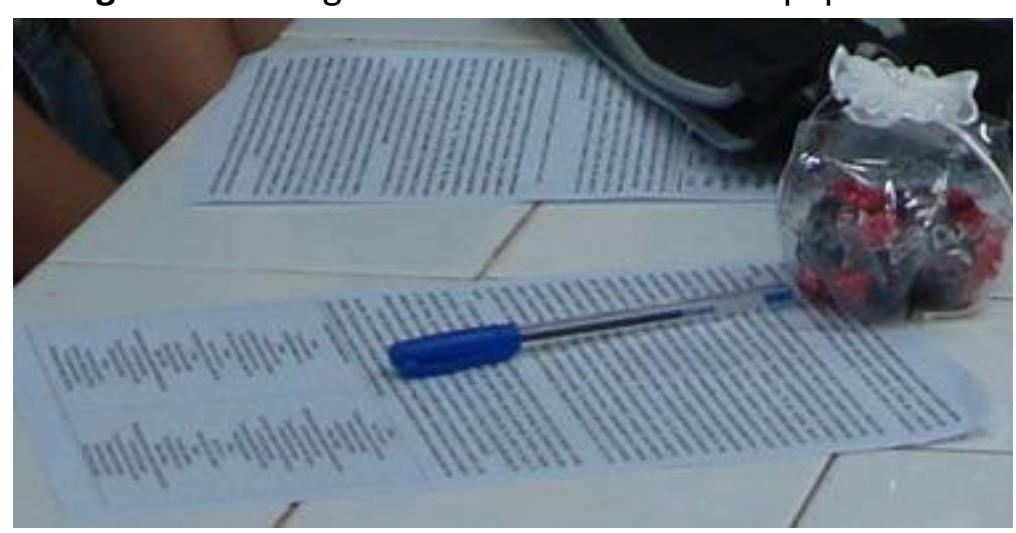

Fonte: Trabalho de campo (maio de 2012)

Este é o local onde a equipe se encontra para desenvolver todas as atividades propostas. Abordou-se de forma interdisciplinar o tema "Noções Básicas sobre Educação Ambiental", como método de aprofundamento dos conceitos; finalidade; categoria e princípios que definem as ações em EA.

Conforme Dias (2004), a preocupação com o meio ambiente tornou-se mais evidente após o contundente ensaio de Thomas Huxley (1863), sobre a interdependência dos seres humanos com os demais seres vivos (Evidências sobre o lugar do homem na natureza) e da publicação do livro "O homem e a natureza: ou geografia física modificada pela ação do homem", do diplomata George Perkin Marsh (1864), documentando o esgotamento dos recursos naturais e prevendo os impactos que a falta de ações preventivas poderiam causar para as gerações futuras.

Patrick Geddes, escocês considerado o "pai da Educação Ambiental", já expressava a sua preocupação com os reflexos da Revolução Industrial, iniciada em 
Ações para conscientização e prática da educação ambiental na cidade de Patos / PB/ Brasil

1779, na Inglaterra, que deu início à urbanização, apontando indicativos de possíveis conseqüências para o ambiente natural (DIAS, 2004).

No entanto, a questão ambiental passou a ganhar grande repercussão através das Conferências das Nações Unidas sobre o Meio ambiente. Para melhor compreensão desta evolução, destacaremos alguns aspectos chave destas entre os anos 1972 e 1992:

1972 - Estocolmo (Suíça): Conferência das Nações Unidas sobre Meio Ambiente Humano. A Educação Ambiental passa a ser considerada como campo de ação pedagógica, adquirindo relevância e vigência internacional.

1974 - Jammi (Finlândia): A Educação Ambiental não é um ramo da ciência ou uma matéria de estudos separada, senão o marco de uma educação integral permanente.

1975 - Organização para a Educação, a Ciência e a Cultura das Nações Unidas (UNESCO) e o Programa das Nações Unidas pra o Meio Ambiente (PNUMA): Seminário Internacional de Educação Ambiental, resultando na Carta de Belgrado.

1977- Tbilisi (URSS): Primeira Conferência Intergovernamental sobre Educação Ambiental (UNESCO/PNUMA) - Meio Ambiente composto pelo meio físico-biótico + meio social e cultural. Relaciona os problemas ambientais com os modelos de desenvolvimento adotados pelo homem.

1987- Moscou (URSS): Congresso Internacional sobre a Educação e Formação relativas ao Meio Ambiente - Gerou o documento Estratégia Internacional em Matéria de Educação e Formação Ambiental para a Década de 90.

1992- Rio (Brasil): Conferência das Nações Unidas sobre o Meio Ambiente, Desenvolvimento sustentável e melhoria da qualidade de vida e a criação da Carta Brasileira de Educação Ambiental.

A partir destes acontecimentos observa-se que aumenta a preocupação com a questão da problemática ambiental e a sustentabilidade que afeta o destino da humanidade, sendo que a equipe de trabalho assinala estes, como um marco importante para atuar na área de Educação Ambiental em todos os setores estratégicos da sociedade iniciando-se pelas escolas e universidades. A relevância do projeto consiste em trabalhar concretamente na transformação local a partir do entendimento dos conceitos base que orientam este estudo, sendo o principal deles o conceito de Educação Ambiental que entendemos como uma forma abrangente de educação que se propõe a atingir todos os cidadãos, inserindo a variável meio ambiente em suas dimensões física, química, biológica, econômica, política e cultural em todas as disciplinas e em todos os meios de transmissão de conhecimentos. As diversas definições de EA variam de acordo com o enfoque dado pela área de conhecimento (biologia, geografia, ciências sociais...). Segundo a Política Nacional de EA (1999) e a Política Estadual de EA do Tocantins (2003):

- "Os processos por meio dos quais o indivíduo e a coletividade constroem valores sociais, conhecimentos, habilidades, atitudes e competências voltadas para a conservação do meio ambiente, bem de uso comum do povo, essencial à sadia 
Ações para conscientização e prática da educação ambiental na cidade de Patos / PB/ Brasil

qualidade de vida e sua sustentabilidade" (Art. 1\%/Lei n 9.795/99-Política Nacional de EA).

- "O processo pedagógico que tem por objetivo a formação e o desenvolvimento do homem e da coletividade com vistas à conservação do meio ambiente equilibrado, abrangendo: a agregação de valores sociais, conhecimentos e habilidades; o estimulo à compreensão dos problemas ambientais; a indicação de alternativas e ao emprego adequado das potencialidades" (Art. $2^{\circ}$ Lei $n^{\circ} 1.374 / 03-$ Política Estadual de EA do Tocantins).

Podemos dizer que a EA é um processo contínuo que vale para toda a vida, examina as questões ambientais desde os pontos de vista locais, nacionais, regionais, e internacionais, para que educandos e educadores possam obter informações sobre as condições ambientais em qualquer área geográfica.

Outro aspecto importante para o desenvolvimento do projeto é definir e atuar sabendo quais são as Finalidades da Educação Ambiental no Brasil:

- Ajudar a compreender claramente, a existência da interdependência econômica, social, política e ecológica, nas zonas urbanas e rurais;

- Proporcionar, a todas as pessoas, a possibilidade de adquirir os conhecimentos, o sentido dos valores, as atitudes, o interesse ativo e as atitudes necessárias para proteger e melhorar o meio ambiente;

- Induzir novas formas de conduta nos indivíduos, nos grupos sociais e na sociedade em seu conjunto, a respeito do meio ambiente.

Portanto, as práticas agrupadas sob o conceito e as finalidades de EA têm sido categorizadas de muitas maneiras, ou resumidamente, trata-se do argumento de que "toda educação é ambiental, assim, toda EA é simplesmente, educação". Podemos dizer que é um processo contínuo, que veio para despertar a tomada de consciência do ser humano diante da natureza, em busca de adquirir mudanças de comportamento e aquisição de novos valores, colocando em prática a responsabilidade de cada um.

Figura 3- Noções Básicas sobre Educação Ambiental no Brasil

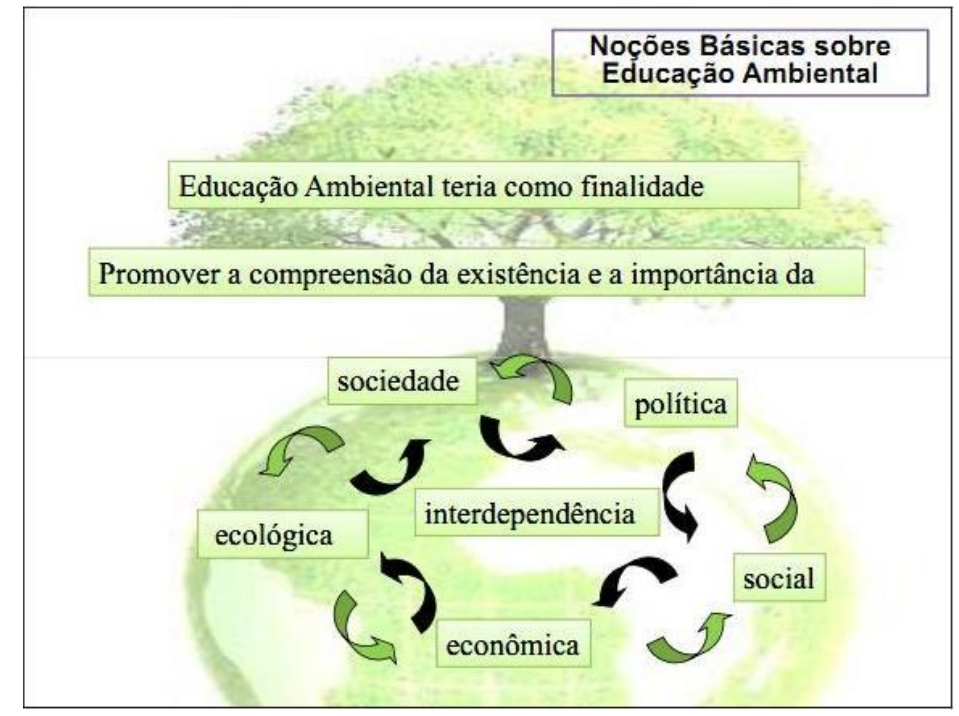

Fonte: os autores 
Durante o desenvolvimento das palestras e oficinas o grupo de alunos das escolas públicas mostrou-se motivado comportando-se como mediadores em ações que envolvessem a transformação socioambiental da realidade local. Para o trabalho com a equipe do PASS o uso de novos enfoques e metodologias propiciou a utilização de um vídeo tendo como tema a música "Tempo de Mudar" (Anexo A), com a finalidade de mostrar que existem outros meios de manifestação e de expressão humana que devem ser contempladas no desenvolvimento de atividades de EA, a exemplos da música, da poesia, da escultura, da pintura, dentre outras que são instrumentos valiosos para sensibilizar, por exprimirem no campo das emoções e dos sentimentos as percepções das pessoas em relação ao meio ambiente.

\section{Material didático digital}

Com o intuito de enriquecer o portal Educador Ambiental Patos/PB, site: http://www.educadorambientalpatos.blogspot.com.br outro colaborador do PASS, é fundamental que o indivíduo se reconheça como parte integrante do ambiente, se sensibilize com os problemas e se sinta responsável pelos impactos por ele gerados, pois entendendo os conceitos que regem a sua dinâmica, poderá agir transformando de forma efetiva o meio onde vive.

Nesta etapa atuamos com a Educação Ambiental Informal, como parte dos processos destinados a ampliar a conscientização pública sobre as questões ambientais através dos meios de comunicação de massa (jornais, revistas, rádios e televisão) e sistemas de informatização (Internet), bancos de dados ambientais, além de bibliotecas, videotecas e filmotecas especializadas. Com esta atividade foram selecionados diversas informações sobre EA, reciclagem, sustentabilidade e compromisso social que resultaram na elaboração de materiais de divulgação digital tal como o boletim: "Especial de Festas Juninas" ademais de três resenhas tratando sobre os filmes "Home, Nosso Planeta, Nossa Casa" e "Lixo Extraordinário", baseados nas Conferências da ONU.

O Filme "Home, Nosso Planeta, Nossa Casa" registra uma viagem única pelo planeta Terra, num sobrevoo que registra as atividades de educação e conscientização destacando o consumo desordenado em vários países e o compromisso social com a preservação e recuperação do Planeta. O documentário "Lixo Extraordinário" registra o choque entre as diferentes culturas e classes sociais, entre pessoas que com educação transformam os materiais reutilizáveis em arte promovendo as mudanças necessárias para preservar o meio onde vivem. Por sua vez o documentário, "Rio+20 - A Humanidade buscando Novos Rumos" relata uma breve linha do tempo apresentando os principais caminhos percorridos na busca de um modelo de desenvolvimento sustentado e sustentável para o Planeta.

Como ressalta Jacobi (1997), as relações entre o ambiente social e o natural estão inseridas na sociedade, onde os atores têm poderes sobre suas ações. Quando desejamos um desenvolvimento que priorize a sustentabilidade socioambiental, é 
Ações para conscientização e prática da educação ambiental na cidade de Patos / PB/ Brasil

necessário priorizar e investir na qualidade de vida e no cultivo de valores que reorientem o pensamento para uma nova postura frente ao mundo que queremos.

\section{Palestras}

Nos dias 05 e 06 de junho de 2012 foram realizadas as palestras junto a "Escola Nosso Lar Tio Juca" na cidade de Patos, PB para professores e alunos de 2aㅡ, 3a e 5a séries. Metodologicamente iniciou-se a atividade com a apresentação de um vídeo da Turma da Mônica: "Um Plano Para Salvar o Planeta", o qual mostrou claramente como o homem está maltratando o Meio Ambiente e também deu orientações de como preservar o Planeta. Na sequência, abordou-se o tema "Proteção ao Meio Ambiente e as Festas Juninas" em palestras para os alunos das turmas da 2a e 3 a séries (21 alunos Figura 4) e para a 5a série (20 alunos - Figura 5).

Figura 4- Palestra "Proteção ao Meio Ambiente e as Festas Juninas" - 2ª da série

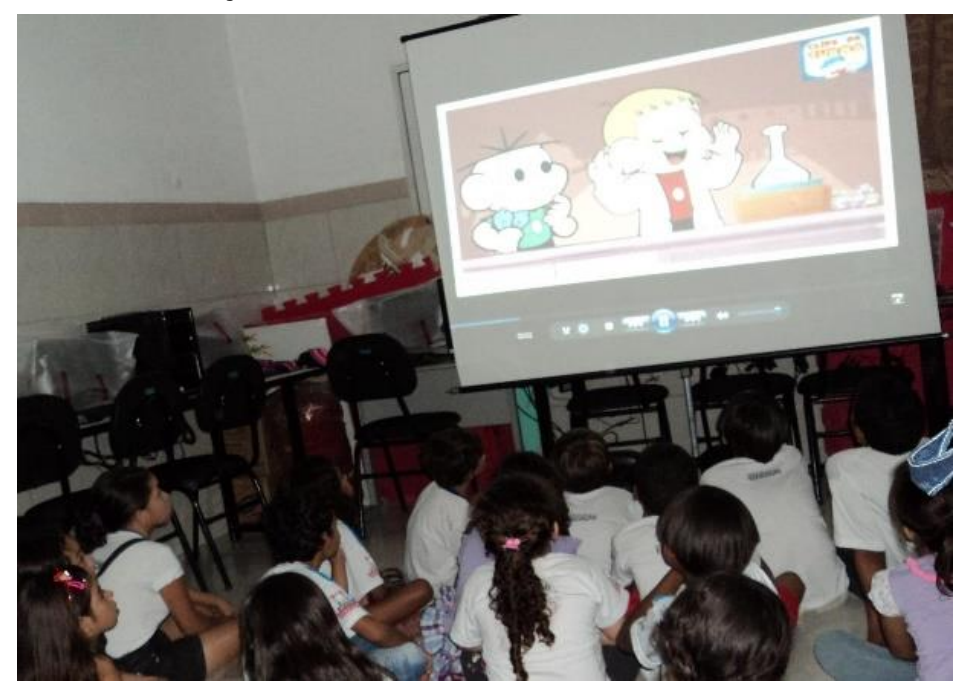

Fonte: Trabalho de campo (junho de 2012)

Figura 5- Palestra "Proteção ao Meio Ambiente e as Festas Juninas" - 5ạ série



Fonte: Trabalho de campo (junho de 2012) 
Segundo Boff (1996, p.134) "para cuidar do planeta precisamos todos passar por uma alfabetização ecológica". Nesse sentido, após a exibição do vídeo, conversamos com os alunos alertando-os sobre a importância de cuidar do nosso Planeta e como fazer para cuidá-lo trabalhando com exemplos. Entende-se que conscientizar sobre a preservação é um começo construtivo especialmente em tempos de Festas Juninas quando o risco de incêndios aumenta porque os fogos de artifício, os balões e o corte de árvores para as fogueiras causam sérios riscos à vida das pessoas e também à natureza.

Num exercício participativo de aprendizagem ecológica desenvolve-se um processo que estimula o pequeno aprendiz a ser um cidadão consciente e comprometido com os princípios de uma vida sustentável. A avaliação foi positiva e segundo as professoras "será importante dar continuidade às palestras porque sempre se aprende uma ideia nova, que possa ser passada adiante".

\section{Oficinas}

As Oficinas foram realizadas na Escola Nosso Lar Tio Juca, com as mesmas turmas que assistiram às palestras, contando com a efetiva participação dos alunos e professores. Com os alunos da 5a série, as atividades desenvolvidas estavam relacionadas à ornamentação de festas juninas, no qual a partir de recortes de jornais e revistas, foram confeccionados adornos e origamis (Foto 4). Para as turmas da 2a e 3 a série, os alunos utilizaram garrafas pet e recortes de revistas para construir um mini cenário de São João, reutilizando os materiais reciclados. A intenção foi mostrar que se pode racionalizar o uso de materiais em nosso cotidiano diminuindo os desperdícios, mas que isso dependerá da atitude de cada um dos sujeitos envolvidos no processo.

\section{Práticas de reciclagem e consumo consciente}

A sociedade está em crise e temos consciência disto, pois estamos enfrentando uma crise de valores morais e éticos sendo que tais situações estão alcançando limites extremos ameaçando a sobrevivência das formas de vida no Planeta Terra. Ações simples como separar o lixo doméstico e reciclar materiais que não estão sendo usados podem ajudar a preservar o planeta e ainda resultar em novos produtos valorizando economicamente o orçamento doméstico. Pensando em práticas sustentáveis para com o meio ambiente deve-se começar dentro de casa e, para isto é necessário conscientização e vontade. É aí que entra a Pedagogia dos três R's do consumo consciente: reduzir, reutilizar e reciclar.

Layrargues (2006 p.88) alerta:

(...) exige-se do cidadão comum uma mudança cultural que resultará em pequenas e relativamente confortáveis mudanças individuais nos hábitos cotidianos na esfera privada, como o consumo sustentável e a reciclagem, por exemplo, com a confiança de que haverá solução tecnológica para todos os impasses modernos, que esses sim, serão discutidos e implementados no âmbito da esfera pública, ainda distantes do cidadão comum. 
Por isso a Educação Ambiental é importante na sociedade de risco em que vivemos atualmente. Ter uma atitude consciente em relação aos nossos hábitos de consumo é a melhor maneira de conseguirmos um futuro sustentável, afinal, a prevenção ainda é a melhor alternativa, pois ao praticar o hábito da reciclagem atuamos com responsabilidade. Outra forma de ação é o consumo responsável num mundo onde a população cresce exponencialmente.

Outra oficina foi realizada na Escola Estadual Ensino Fundamental e Médio Professor José Gomes Alves, também no município de Patos, PB, bairro Jatobá, abordando o tema: "Repensar, reduzir, reutilizar, reciclar, atitude consciente". Foi realizada no dia 07 de novembro de 2012, com a turma do "F1"- Ensino Médio (Figura 7).

As atividades foram desenvolvidas em diferentes etapas. A primeira consistiu em uma breve explanação sobre o Projeto PASS, explicação sobre a Pedagogia dos 3R's, sua importância e atitude consciente; jogo dos coletores sendo que na oficina trabalhou-se com a reutilização de garrafas de iogurte (plástico) com os quais foram feitos porta celulares e com as caixinhas de leite que foram reutilizadas para fazer caixas para presentear (papel).

Figura 6 - Oficina: Escola Nosso Lar Tio Juca

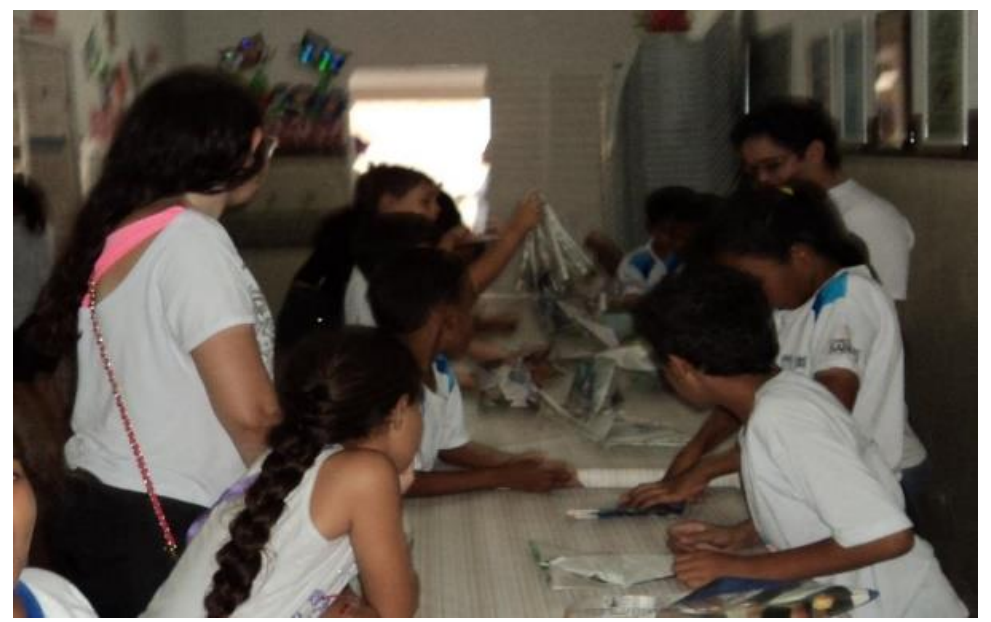

Fonte: Trabalho de campo, oficina (jun. e nov. de 2012)

Figura 7 - Oficina: E.E.F.M. Professor José Gomes Alves

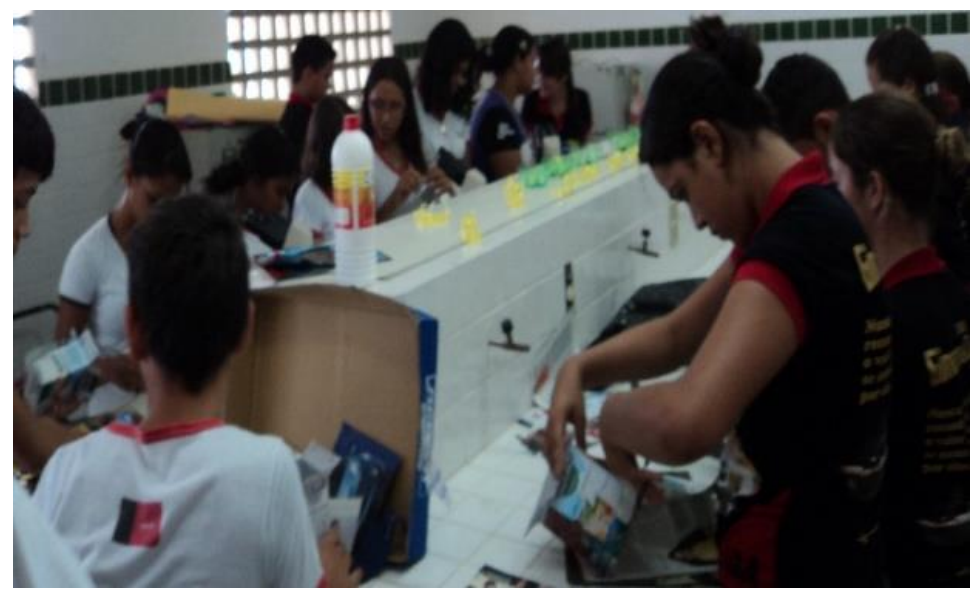

Fonte: Trabalho de campo, oficina (jun. e nov. de 2012) 
Como conclusão desta etapa, podemos destacar que o princípio básico de qualquer atividade de Educação Formal é estimular a abordagem interdisciplinar dos conteúdos ambientais, trabalhando-os de forma transversal ao currículo básico dentro das diferentes disciplinas já existentes. Como principal instrumento temos a escola (pública estadual ou municipal e privada), onde se faz necessária uma ação continuada, que contribua efetivamente na ampliação e no enriquecimento da questão ambiental, propondo ações não específicas por disciplina, mas abrangendo as diferentes áreas do conhecimento e servindo como meio estimulador de algumas ações e Programas Permanentes de Educação Ambiental Escolar

\section{Pesquisa de matérias ou notícias}

Destaca-se que como meio de divulgação impressa ou online, o PASS procurou sempre manter atualizado seu portal com informações sobre as ações do projeto em execução, a equipe, textos, artigos, informações específicas da área como: reciclagem, sustentabilidade, meio ambiente. Aprimorando-o trouxe noticiários, matérias ou pesquisas de outros sites, sendo fiel às fontes originais.

Deste compromisso com o PASS surgiu necessidade de contribuir com matérias e notícias coletados em diferentes fontes e enviados para o e-mail do Florestal Recicla. Após aprovação das notícias enviadas, o responsável se encarregava de publicá-los no Boletim Florestal Recicla (Anexo B): "Brasileiros Estimam Problemas de Abastecimento de Água no Futuro", fonte pesquisada no Portal EcoD.

Segundo a pesquisa, a realização de estudos relacionados à Educação Ambiental e Sustentabilidade são os porta-vozes para uma vida mais saudável. Essas informações assumem um papel cada vez mais relevante, no tempo e espaço, e tem sido alvo de cursos, debates, estudos, pesquisas, através da multimídia, internet, e de muito marketing de interesse de alguns pequenos grupos sociais entre outros.

\section{Criação de objetos reutilizando materiais recicláveis}

Reconhecendo que a ludicidade facilita o ensino-aprendizagem, criou-se alguns objetos e brinquedos como forma de dinamizar a interação do ensino durante as apresentações e oficinas desenvolvidas (Figura 8).

Figura 8 - Criação de objetos com materiais reutilizáveis, replicando experiências
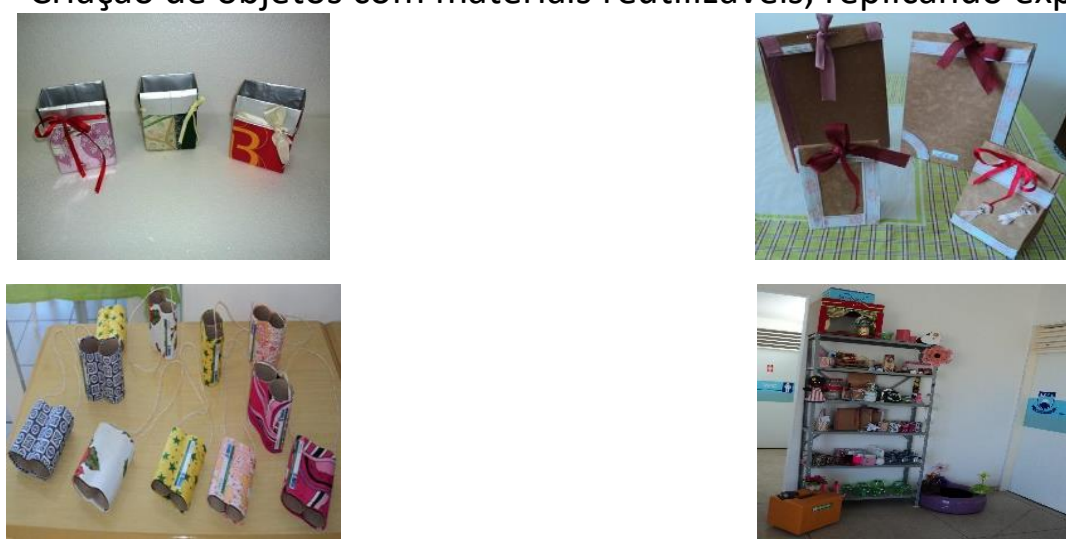

Fonte: Trabalho de campo (jul, ago, out e dez de 2012

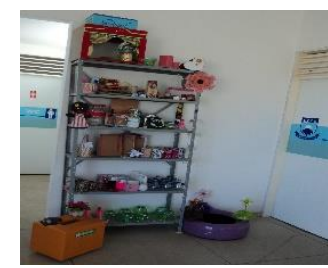


Vimos que o reaproveitamento dos resíduos sólidos é muito importante, ao contrário do que se pensa, esses materiais definidos como sendo obsoletos, possuem um grande potencial de reaproveitamento, pois, em sua maioria, podem ser reciclados, conservando assim os recursos naturais não renováveis. Replicando as experiências de maneira interdisciplinar, se verifica que a atividade com os objetos feitos de materiais recicláveis (Foto 6) também podem ser desenvolvidos com a comunidade local. Neste caso os principais objetivos seriam: melhorar a qualidade de vida da comunidade e fortalecer a cidadania, seguindo certos hábitos como poupar economia energia e água, combater o desperdício de matérias-primas, redução da poluição do ar e sonora, coleta seletiva e reciclagem... Ações simples que podem se tornar hábitos por meio de Educação Ambiental Não-Formal. Conhecimento, EA e compromisso social são essenciais para a inserção política, social e econômica da população. (Apêndice).

A Educação Ambiental é a chave para a resolução de muitos dos problemas brasileiros, "pois é um tipo de educação que não necessita de graus de escolaridade, pode ser desenvolvida entre crianças e adultos, mesmo sem serem alfabetizados" (BRASIL e SANTOS, 2004, p.33).

\section{Conclusão}

Independentemente de qualquer público-alvo, digamos que pela primeira vez, o homem compreendeu a importância de um novo humanismo, que ele é um habitante desse mundo e que deve pensar e agir com sabedoria, resgatando os ideais e valores do homem como ser ambiental. Com base nos trabalhos desenvolvidos e de acordo com a análise dos resultados e discussões, conclui-se que o PASS se constitui numa eficiente ferramenta para a promoção da Educação Ambiental, porque contempla a troca de experiências e relações com diversos segmentos da sociedade. Proporciona aos alunos vivenciar experiências participativas e harmoniosas com o ambiente em que vivem, permitindo que percebam seus hábitos, olhando-os com uma visão crítica, holística, trazendo a necessidade de mudança de valores, atitudes e condutas.

Reconhece-se que as realizações destes trabalhos para a educação promovem ações que despertam o compromisso com a sustentabilidade socioambiental: conhecer para interagir é um processo para toda a vida.

Percebe-se que a sociedade atual se vê forçada a pensar sobre a sua existência e os impactos que causa ao ambiente e, sobretudo, suas consequências e se faz necessário discutir a educação sustentável a partir da educação para o consumo consciente. 0 processo de ensino-aprendizagem é um fator relevante na formação do sujeito e da cidadania. Nesta abordagem educacional, na perspectiva da Educação Ambiental em Patos, PB, estamos convencidos da amplitude e dos problemas ambientais e sociais que a sociedade enfrenta. E é nesta perspectiva que todos precisam se engajar para lidar com a complexidade da realidade, alertando que a educação deverá inspirar mudanças não apenas no comportamento cidadão, mas também junto aos responsáveis pelas decisões que incidem sobre o meio ambiente. 
No desenvolvimento do projeto, os educadores (autora e coautores) buscaram atuar e oferecer contribuições relevantes às questões socioambientais, lançaram pequenas sementes para formar mentes conscientes do seu papel na sociedade, no Meio e na própria vida, capacitando os participantes para que exerçam com dignidade sua cidadania. Porque entendemos que a Educação Ambiental pode se constituir num espaço revigorado da vida escolar e da prática pedagógica, reavivando o debate dentro e fora da escola, permitindo uma maior conexão com a realidade dos educandos, possibilitando uma ação consciente e transformadora das posturas em relação ao mundo e aos semelhantes.

\section{Referências}

BOFF, L. Ecologia, mundialização e espiritualidade: emergência de um novo paradigma. São Paulo: Ática, 1996, 180p.

BRASIL, A. M.; SANTOS, F. Equilíbrio Ambiental \& Resíduos na Sociedade Moderna: São Paulo: FAARTE, 2004, 224p.

CARVALHO, I. C.de M. Educação Ambiental: a formação do sujeito ecológico. 4o ed. São Paulo: Cortez, 2008, 256p.

DIAS, G. F. Educação Ambiental: princípios e práticas. 9o ed. São Paulo: Gaia, 2004, 551p. GRÜN, M. Ética e Educação Ambiental: a conexão necessária. São Paulo: Papirus, 1996, $126 \mathrm{p}$.

JACOBI, P. Meio ambiente urbano e sustentabilidade: alguns elementos para a reflexão. In: CAVALCANTI, C. (org.). Meio ambiente, desenvolvimento sustentável e políticas públicas. São Paulo: Cortez, 1997, p. 384-390.

LAYRARGUES, P.P. Muito além da natureza: Educação Ambiental e reprodução social. In: Loureiro, C.F.B.; Layrargues, P.P. \& Castro, R.C. de (Orgs.). Pensamento complexo, dialética e educação ambiental. São Paulo: Cortez, 2006, p.72-103 
Ações para conscientização e prática da educação ambiental na cidade de Patos / PB/

Brasil

\section{APÊNDICE \\ Passo a Passo: Caixa de leite para presentear}

PASS - Programa de Ações para a Sustentabilidade Socioambiental - Projeto Florestal Recicla

\section{Caixa de leite para presentear}

Tempo aproximado: 40 minutos.

Indicação: Público em Geral.

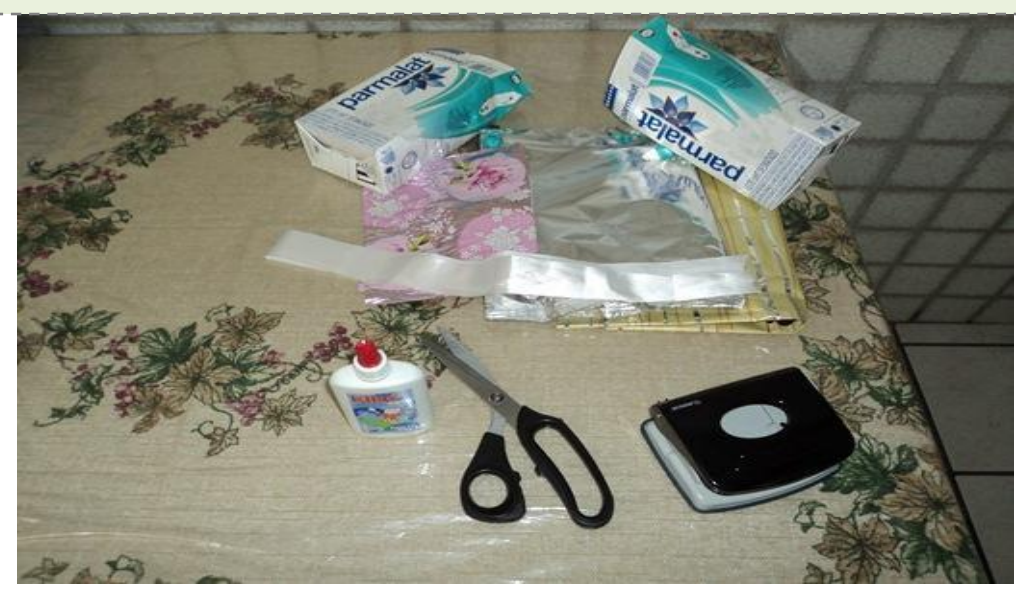

\section{Material:}

Tesoura;

Régua;

Cola;

Papel de presente; ou papel colorido;

Fita mimosa;

Perfurador de papel;

Caixa de leite;

Lápis ou caneta.

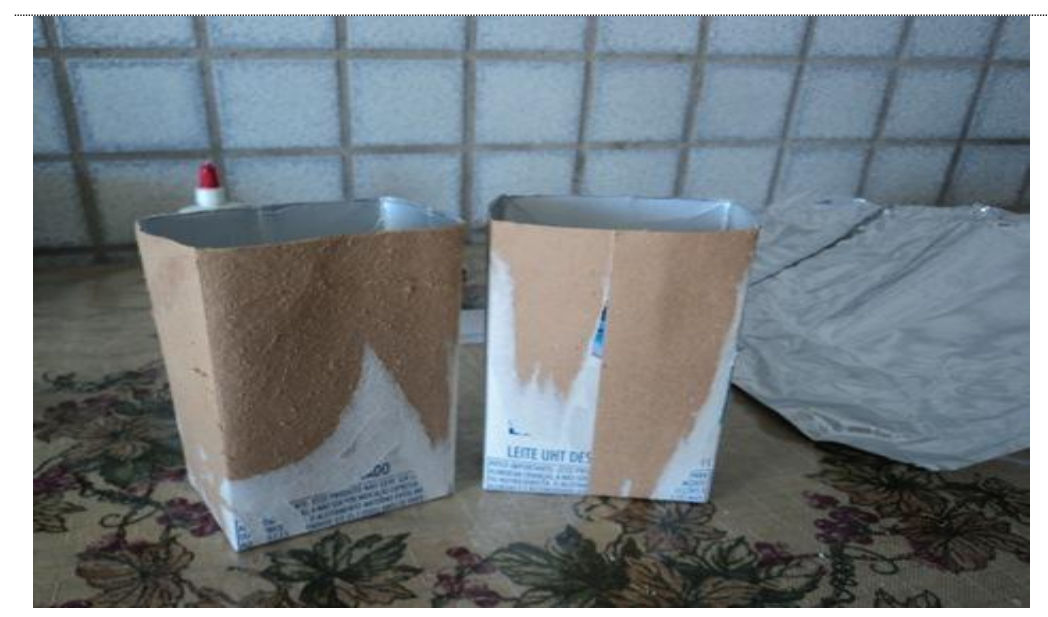

Primeiramente lavar a caixa e deixar secar.

Abrir a parte de cima (cortar reto) bem onde se encontra a marca da caixa.

O fundo da caixa não precisa desprender.

Tirar somente a estampa (descascar) deixando-a a cor do papel. Pois dependendo do papel pode transparecer o fundo da caixa com o seu slogan.

Cuidado para não ficar muito fina.

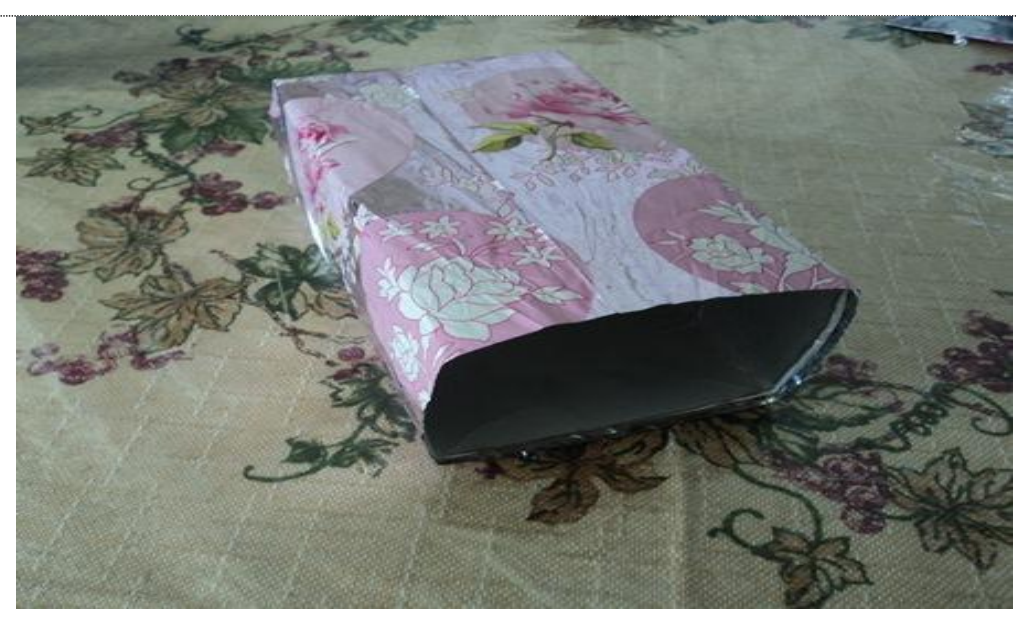

Passe cola na caixa após cobrir com papel presente ou outro colorido, conforme figura ao lado. 

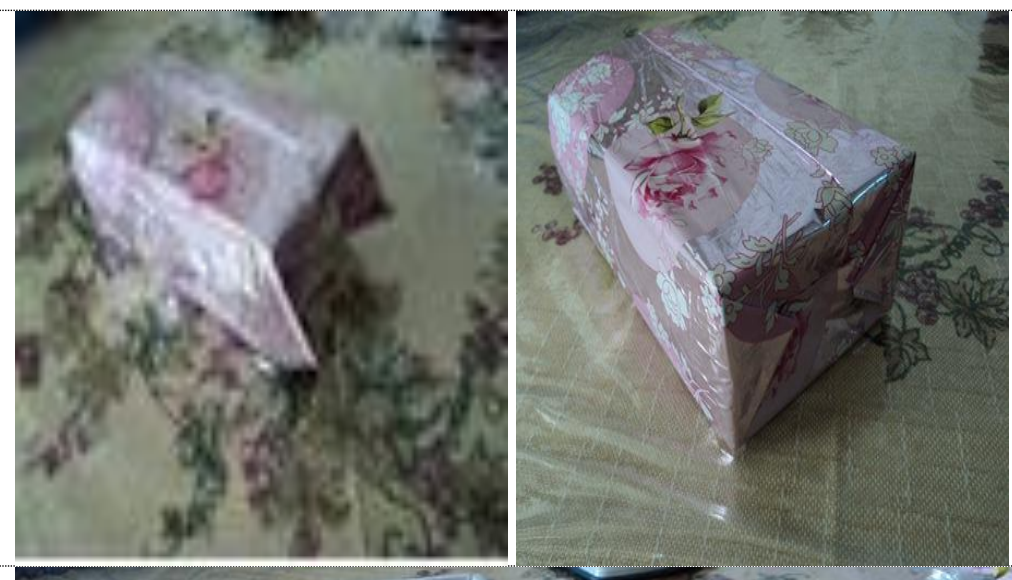

Após dobrar os cantos com o papel presente, conforme figura, passe cola para fechar o fundo da caixa.



Para ficarem aberto estas quatro partes para baixo da caixa, faz-se o seguinte:

Da marca da dobra da caixa é só seguir e cortar bem retinha, medindo com a régua mais ou menos $4 \mathrm{~cm}$ de cima para baixo e cortar em comprido os cantos. Em seguida dobrar as abas para o lado de fora.

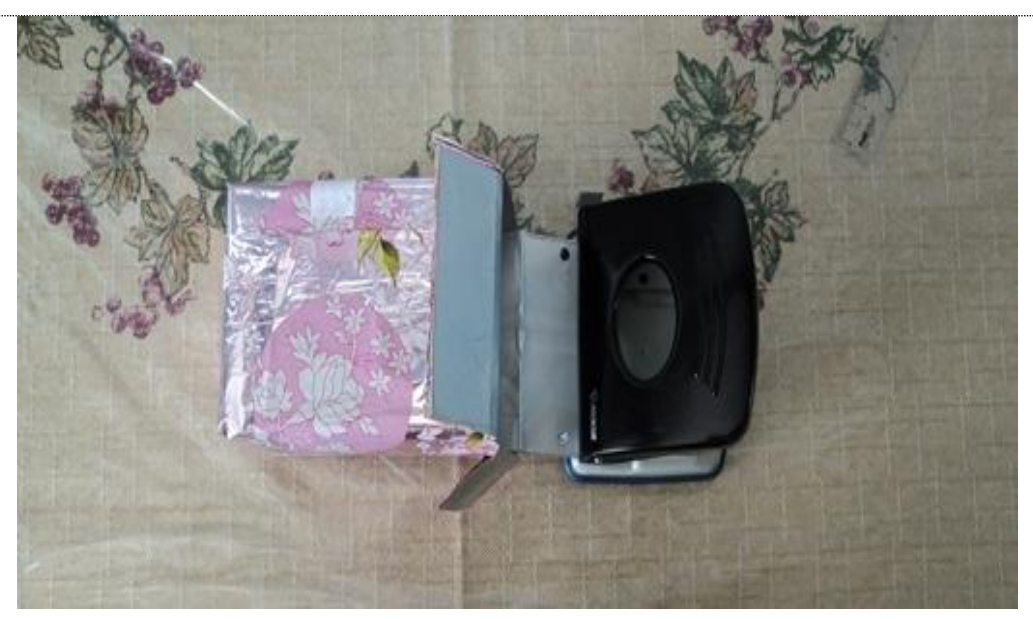

Após os quatro cantos da caixa para o lado de fora se faz os furos com perfurador de papel, como mostra figura ao lado.

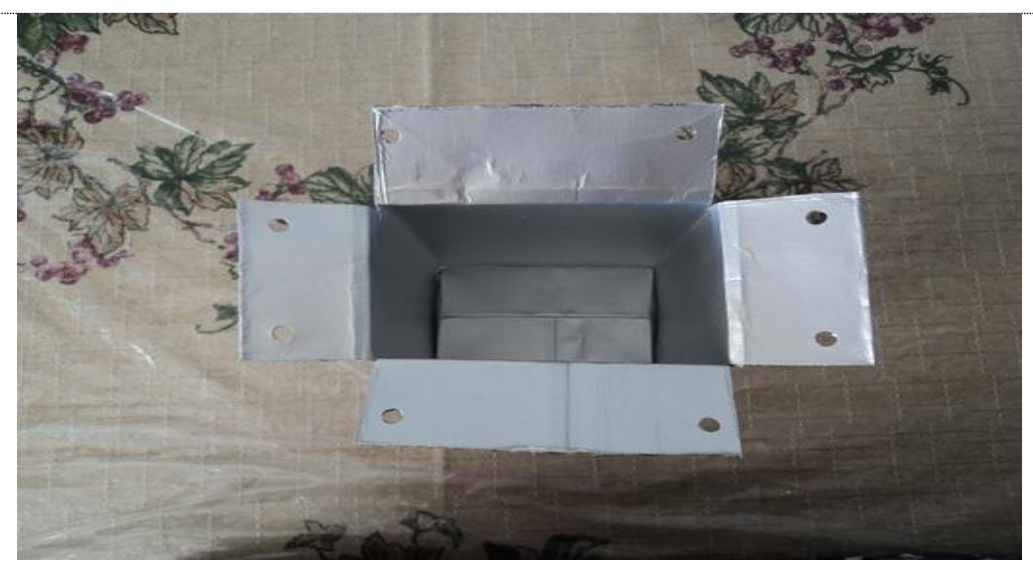

Feito as aberturas, duas em cada canto das caixas, obteve-se a ilustração, como segue figura ao lado. 


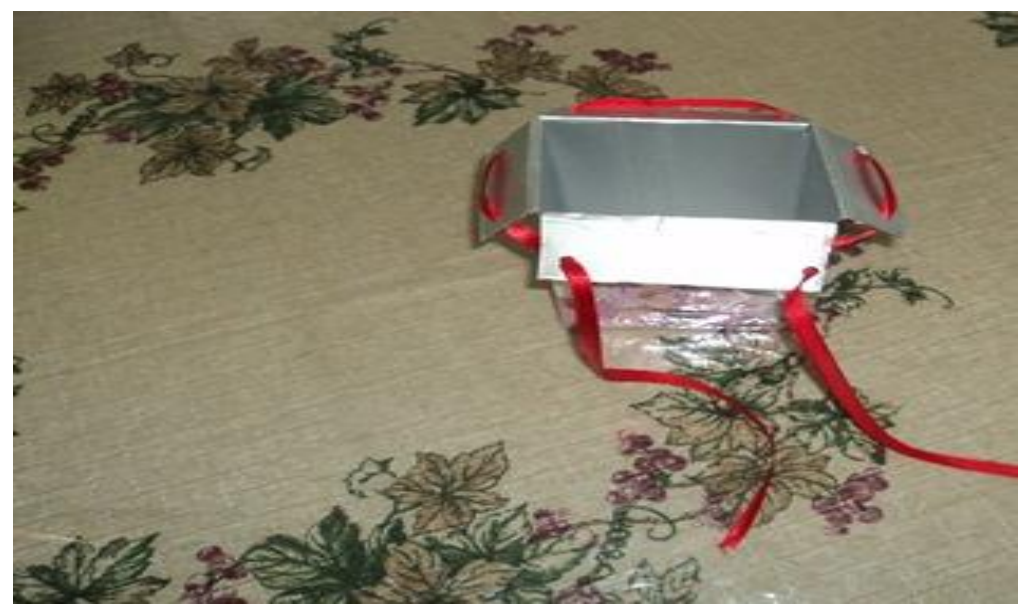

Obs: Antes de colocar a fita mimosa na caixa, seria bom passar as pontas da fita no fogo do isqueiro ou vela para não o risco de desfiar.

Por fim, insere a fita nos buraquinhos feitos na caixa envolvendo-os todos.

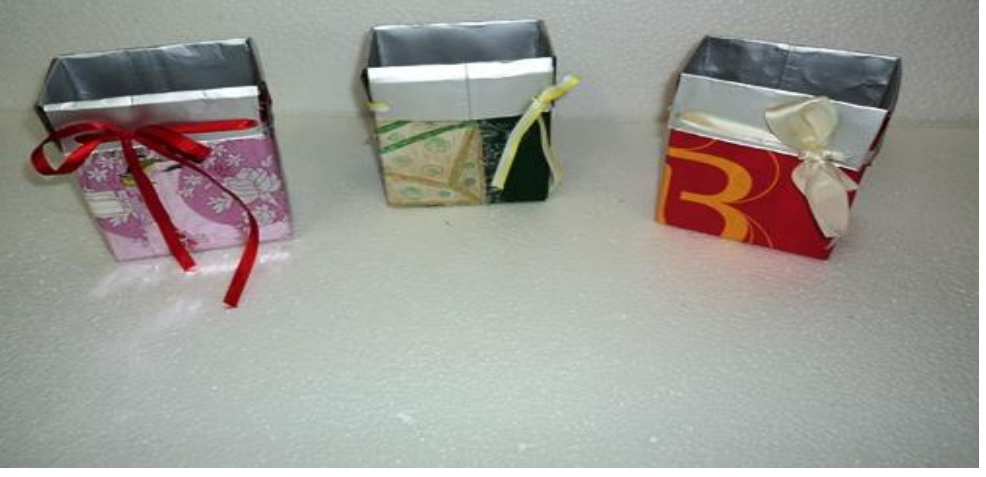

Esta pronta à sua caixinha de presente para presentear ou até mesmo servindo como enfeite para vasinho de flores.

Modelo:

Caixinha de presente

Altura aproximadamente $=12,50 \mathrm{~cm}$. Comprimento aproximadamente $=9,50 \mathrm{~cm}$. Largura aproximadamente $=6,50 \mathrm{~cm}$.

Este material e muitos outros, você encontra no portal Educador Ambiental - Patos, PB, através do site: http://www.educadorambientalpatos.blogspot.com.br 
Ações para conscientização e prática da educação ambiental na cidade de Patos / PB/ Brasil

ANEXO A - Música "Tempo de Mudar" com Maisa e Eliana. Categoria Educação. Data do vídeo 30 de agosto de 2008. Disponível em: http://www.youtube.com/watch?v=FgHOHyrBCaY

Tempo de Mudar (part. Eliana) Maisa




O Boletim Florestal Recicla pode ser encontrado no site:

http://www.florestalrecicla.com, constituído por notas e notícias e também relacionadas às ações atuais do projeto. 
Ações para conscientização e prática da educação ambiental na cidade de Patos / PB/ Brasil

Sobre os autores:

Alana Candeia de Melo, Centro Universitário de Patos- UNIFIP, PB, Diretora Acadêmica. Email: acmelopb@gmail.com

Carina Cristina Agnes Calegari, Centro Universitário de Patos - Patos - Paraíba - Brasil, especialista em Educação Ambiental. Email: carinaagnes@yahoo.com.br

Edevaldo da Silva, Universidade Federal de Campina Grande, campus Patos, PB, professor da Unidade Acadêmica de Ciências Biológicas. Email: edevaldos@yahoo.com.br

Joedla Rodrigues de Lima, Universidade Federal de Campina Grande, campus Patos, PB, professora da Unidade Acadêmica Engenharia Florestal. Email: joedlalima@yahoo.com.br

Leandro Calegari, Universidade Federal de Campina Grande - Patos - Paraíba - Brasil, professor da Unidade Acadêmica Engenharia Florestal. Email: calegari@cstr.ufcg.edu.br 